\title{
Concepções de humanização de profissionais em Unidades de Terapia Intensiva Neonatal
}

\author{
Conceptions of humanization of health professionals \\ in Neonatal Intensive Therapy Units
}

Cláudia Paresqui ROSEIRO ${ }^{1}$

Kely Maria Pereira de PAULA ${ }^{1}$

\begin{abstract}
Resumo
Considerando-se a importância das estratégias de humanização e intervenção hospitalar no atendimento ao recém-nascido enfermo, esta pesquisa investigou a concepção de humanização da equipe de profissionais de três Unidades de Terapia Intensiva Neonatal da Região Metropolitana da Grande Vitória, Espírito Santo. Participaram do estudo 29 profissionais de saúde, entre médicos, enfermeiros, fonoaudiólogos, fisioterapeutas e técnicos de enfermagem, os quais responderam a roteiros de entrevistas semiestruturadas. Os dados das entrevistas foram processados pelo software Alceste e submetidos à Análise de Conteúdo. Concluiu-se que os profissionais compreendem o cuidado humanizado a partir do resgate da perspectiva afetiva, em oposição ao modelo médico-tecnicista de atenção à saúde, ou seja, com ênfase nos aspectos emocionais que envolvem sua relação com o bebê e com o trabalho em Neonatologia. A participação da família foi o aspecto mais relevante para os profissionais, que expressaram a importância da permanência dos pais na unidade de terapia e sua participação nos cuidados ao recém-nascido.
\end{abstract}

Palavras-chave: Estratégias; Humanização da assistência; Recém-nascido; Unidades de Terapia Intensiva.

\begin{abstract}
Considering the importance of hospital humanization and intervention strategies in the treatment of the newborn patient, this research investigated the conception of humanization of health professionals in three Neonatal Intensive Care Units in the metropolitan area of Vitória, Espírito Santo. The study included 29 health professionals (doctors, nurses, audiologists, physiotherapists and practical nurses) who were asked to answer a semi-structured interview. Interview data were processed using the Alceste software and submitted to Content Analysis. It was concluded that professionals understand humanized care from an affective perspective, as opposed to the medical-technicist approach of health care with emphasis on the emotional aspects that involve their relationship with the baby and their work in neonatology. Family participation was the most notable aspect in the professional's view who expressed the importance of parents staying in the Neonatal Intensive Care Units and their participation in providing care to the newborn.
\end{abstract}

Keywords: Strategies; Humanization of assistence; Infant, newborn; Intensive Care Unit.

$\nabla \nabla \nabla$

1 Universidade Federal do Espírito Santo, Departamento de Psicologia Social e do Desenvolvimento, Programa de Pós-Graduação em Psicologia. Av. Fernando Ferrari, 514, Goiabeiras, 29075-910, Vitória, ES, Brasil. Correspondência para/Correspondence to: K.M.P. PAULA. E-mail: <kelymppaula@gmail.com>.

Artigo elaborado a partir da dissertação de C.P. ROSEIRO, intitulada "Cuidado ao Recém-nascido em UTIN: concepções e práticas de humanização". Universidade Federal do Espírito Santo, 2010.

Apoio: Coordenação de Aperfeiçoamento de Pessoal de Nível Superior, Fundo de Apoio à Ciência e Tecnologia e Fundação de Amparo à Pesquisa do Espírito Santo. 
A Política Nacional de Humanização (PNH) surge como uma proposta de aprimoramento da qualidade no atendimento à saúde da população, articulando os avanços tecnológicos com o acolhimento e destacando o processo subjetivo do ato de cuidado (Brasil, 2005). Para tanto, um conjunto de estratégias busca tornar os princípios do Sistema Único de Saúde (SUS) disparadores de mudanças nos modelos de atenção e gestão das práticas de saúde no País (Brasil, 2004).

Na assistência à criança, em âmbito ministerial, a Humanização direciona-se mais ao atendimento do bebê Pré-Termo (PT) e de Baixo Peso (BP), internado em Unidade de Terapia Intensiva Neonatal (UTIN). A Atenção Humanizada ao Recém-Nascido de Baixo Peso - Método Canguru (AHRNBP-MC) é o modelo de assistência preconizado, incluído na política governamental a partir de 2000 , e propõe um cuidado integral ao Recém-Nascido (RN) e a sua família (Lamy, 2006; Véras, Vieira, \& Morais, 2010). Sendo assim, a atenção humanizada ao RN internado em UTIN tem como meta elevar o padrão técnico de atendimento, conjugado à assistência integral ao bebê e a sua família, por meio do aprimoramento da conduta técnica e da postura profissional (Brasil, 2002; Kernkraut \& Andreoli, 2008).

Nesse sentido, partindo da importância da atuação da equipe no contexto hospitalar, vários estudos têm voltado seu interesse para o profissional de saúde e suas percepções sobre o processo de trabalho e a humanização do cuidado (Beck, Gonzalez, Denardin, Trindade, \& Lautert, 2007; Costa, Figueiredo, \& Shawrich, 2009; Cunha \& Benevides, 2012; Henning, Gomes, \& Gianini, 2006; Rolim \& Cardoso, 2006). Em revisão da literatura, Goulart e Chiari (2010) discutem a humanização a partir de sua concepção como política de saúde e como prática profissional, apresentando-a como um objetivo permanente e como uma meta central a ser buscada em qualquer projeto nessa área.

Uma revisão histórica sobre o conceito de humanização foi realizada por Deslandes (2006), que aponta vários fatores de "desumanização" na área da saúde, tanto de ordem estrutural (como a formação profissional biomédica, a organização dos 110 serviços de saúde, a estrutura hierárquica social e de prestação de cuidados) como de ordem interacional (relações de conflito, subordinação ou cooperação entre profissionais e pacientes). Esses fatores são decorrentes, em grande parte, da ênfase dada à técnica e à racionalidade científica, em detrimento dos aspectos mais subjetivos do ato de cuidado na constituição das instituições hospitalares e do saber médico (Costa, et al., 2009; Martins, 2004).

Nesse contexto, a norma de AHRNBP-MC surgiu como uma tentativa de mudar a postura na abordagem perinatal, com a humanização da assistência prestada. A partir de um equilíbrio no atendimento às necessidades biológicas, ambientais e familiares, buscou-se uma adaptação técnica e atitudinal que pudesse promover a humanização do atendimento. Dessa forma, a AHRNBP-MC objetiva maior apego entre mãe e criança, incentivo ao aleitamento materno, bem como melhor desenvolvimento e segurança infantil (Brasil, 2002).

Esta pesquisa teve por objetivo geral investigar a concepção de humanização e de cuidado humanizado da equipe de profissionais da UTIN, bem como o relato de suas práticas de assistência ao RN. Sessões de observação foram realizadas nas UTIN para identificar os princípios norteadores da AHRNBP-MC na rotina dos profissionais. Todavia, considerando o propósito deste artigo, descrevem-se os dados advindos das entrevistas com os profissionais, concernentes a suas concepções de humanização bem como seus relatos sobre a assistência ao bebê e família.

\section{Método}

\section{Participantes}

A pesquisa foi realizada nas unidades neonatais de três hospitais públicos da Região Metropolitana de Vitória (ES). Participaram do estudo 29 profissionais de saúde atuantes na UTIN, sendo 3 médicos, 3 enfermeiras, 3 fonoaudiólogas, 3 fisioterapeutas, 2 psicólogas e 15 técnicas de enfermagem, compondo uma amostra de conveniência. Em cada hospital foi possível estabelecer a participação 
de um representante de cada uma dessas especialidades de nível superior e cinco representantes de nível médio. A idade média dos participantes foi 32 anos (22-49 anos), sendo somente um participante do sexo masculino; e 5,8 anos o tempo médio de atuação em UTIN, que variou de 1 mês a 20 anos.

O projeto foi aprovado pelo Comitê de Ética em Pesquisa da Universidade Federal do Espírito Santo (CEP/UFES) e pelo Comitê de Ética em Pesquisa da Secretaria de Saúde (CEP/SESA) do mesmo Estado. Todos os participantes assinaram um Termo de Consentimento Livre e Esclarecido antes de sua inclusão na amostra.

\section{Instrumentos}

Foi aplicado um roteiro de entrevista do tipo semiestruturado, incluindo questões sobre concepções de humanização e práticas desenvolvidas para humanizar o atendimento na UTIN (e.g. "O que você já ouviu falar sobre humanização na área da saúde?", "O que é humanização para você?" e "Que ações você realiza no sentido de humanizar seu atendimento na UTIN?"). Entrevistas individuais foram realizadas no horário de trabalho dos profissionais, em um ambiente reservado, e gravadas em áudio.

\section{Procedimentos}

Os dados obtidos pelas entrevistas foram transcritos literalmente e submetidos a análise quantitativa por meio do software Alceste (Camargo, 2005), o qual realiza uma análise lexical de dados textuais, efetuando cálculos sobre a coocorrência de palavras num conjunto de texto (Camargo, 2005; Nascimento \& Menandro, 2006). O programa realiza uma primeira classificação estatística de enunciados simples do corpus (conjunto de texto) estudado, por meio da distribuição das palavras, apreendendo as que lhe são mais características (Cortez, 2006).

O corpus analisado foi composto pelas entrevistas realizadas com os profissionais de saúde, divididas em três segmentos referentes às temáticas investigadas: a) concepções de humanização; b) concepções sobre o bebê; e c) práticas de cuidado, totalizando 87 Unidades de Contexto Inicial (UCI). As UCI foram separadas por linhas de comando ou "linhas com asterisco" que informavam a identificação do participante, e variáveis importantes ao delineamento da pesquisa, tais como: hospital onde o profissional trabalhava, idade, cargo, tempo de atuação em UTIN e as referidas temáticas.

Em conjunto com a análise do Alceste, foi realizada uma Análise de Conteúdo (Bardin, 2004), como uma forma complementar de tratamento dos dados, buscando realizar uma análise mais compreensiva do discurso a partir do mapeamento inicial do corpus realizada pelo software. Essa análise conjugada é um procedimento importante, na medida em que torna possível aliar à análise estatística do vocabulário de um discurso uma análise abrangente de seus significados (Nascimento \& Menandro, 2006).

\section{Resultados}

A partir dos dados das entrevistas dos profissionais de saúde, o software Alceste gerou cinco classes, subdividindo as Unidades de Contexto Elementar (UCE) em dois grandes blocos: a) Relacional: agrupando as classes humanização, sentimentos em relação ao trabalho e participação da família, respectivamente; e b) Técnico: com as classes estimulação oral e cuidados com o ambiente sensorial. Os conteúdos dos dois blocos encontram-se distantes entre si, determinados pelas posições opostas que assumem no plano fatorial, o que permitiu analisar que os aspectos relacionais (valores e sentimentos) ficaram distanciados dos aspectos técnicos quando os profissionais falaram sobre a assistência humanizada. O resultado da Análise Fatorial de Correspondência (AFC), com a representação gráfica das relações entre as classes e entre suas palavras mais significativas, pode ser visualizado na Figura 1.

As três classes reunidas no bloco Relacional (humanização, sentimentos em relação ao trabalho e participação da família) apresentam conteúdos mais próximos entre si, tratando dos valores e sentimentos dos profissionais em relação à humanização, 


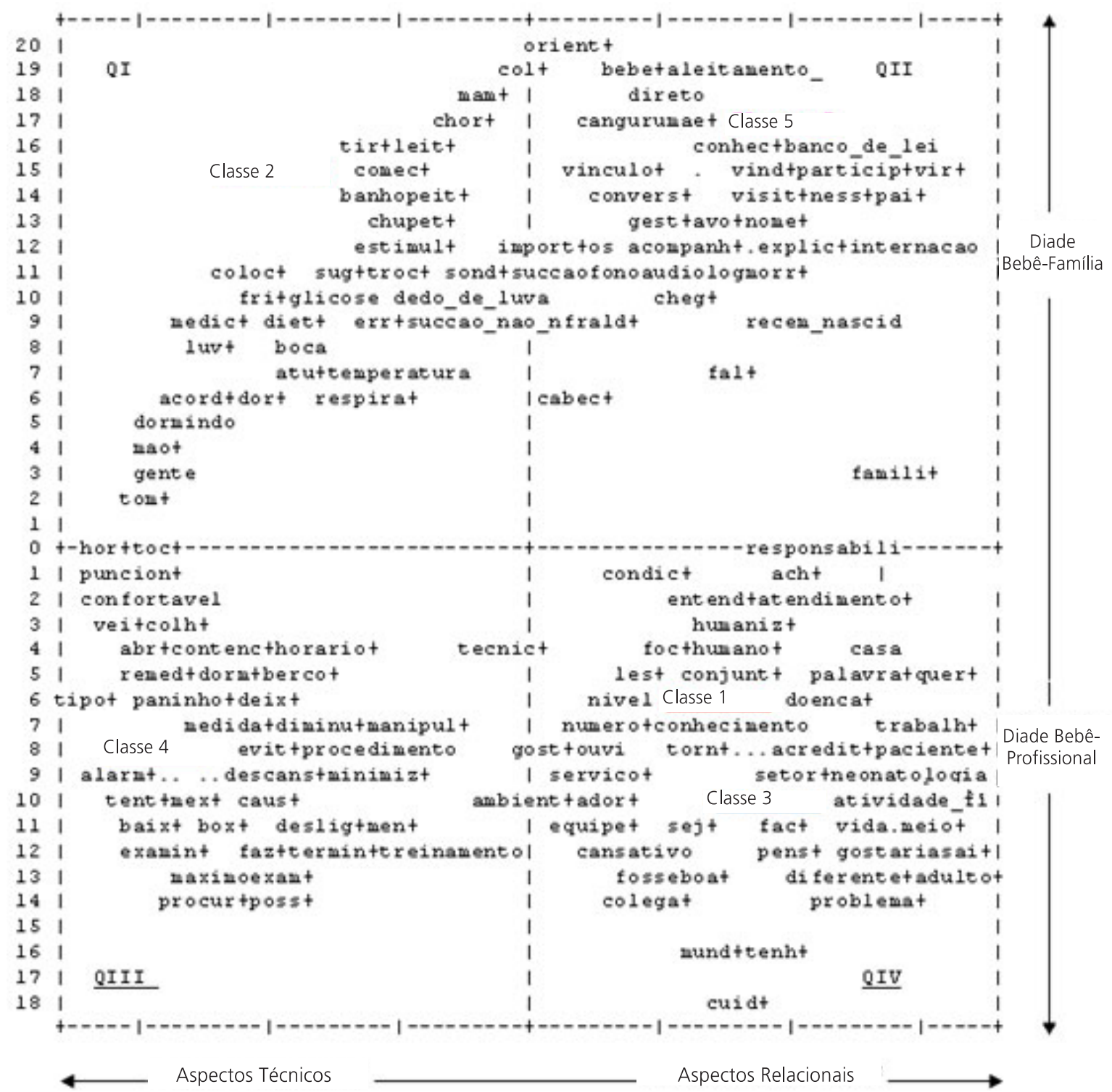

Figura 1. Análise Fatorial de Correspondência (AFC): correlação entre palavras significativas nos planos fatoriais.

e de sua relação com o bebê e com o trabalho. Na segunda divisão do bloco Relacional, permanecem juntas as classes humanização e sentimentos em relação ao trabalho, o que aponta para uma forte ligação entre as duas.

No bloco Técnico encontram-se as classes estimulação oral e cuidados com o ambiente sensorial, as quais se apresentam relacionadas, abordando questões mais formais da assistência ao bebê como os cuidados padrão e o saber técnico dos profissionais que atendem ao RN internado em UTIN. Trata-se das rotinas e técnicas, direcionadas principalmente a: adequação da luminosidade e ruído do ambiente, estimulação oral, sucção, cuidado com a manipulação, manutenção da temperatura e procedimentos para amenizar a dor do RN.

As classes obtidas a partir do software Alceste serão apresentadas de forma mais detalhada, juntamente com a análise de seu conteúdo.

\section{Humanização}

Nessa classe estão colocadas as concepções de humanização dos profissionais entrevistados, o que eles pensam e o que já ouviram falar sobre a temática na área da saúde. As palavras plenas mais 
representativas foram humanização, paciente, doença, humano, tratar, compromisso, mecânica, conjunto, família, equipe, responsabilidade, tecnicista, diferente, qualidade de vida, amor, bem-estar, sujeito e envolvimento.

O entendimento de cuidado humanizado encontra-se em oposição à assistência mecânica e tecnicista, focada na doença. A humanização envolve compromisso e responsabilidade, objetivando a qualidade de vida e bem-estar do paciente, considerando-o como indivíduo. Trata-se de um cuidado diferente, que busca um tratamento por completo, a partir do trabalho em equipe. Algumas falas ilustram essa classe:

É uma palavra pesada que teve que ser usada para nós profissionais da saúde tecnicista, porque nosso paciente está numa posição passiva, submissa, a gente tem que entender que ele depende exclusivamente da gente e que a gente precisa oferecer não só uma medicação, um procedimento, mas um cuidado global (Enfermeira 1).

Transformar o espaço hospitalar num espaço mais acolhedor, que possa ir além da doença (Psicóloga 1).

Amor, porque se eu não amar o que eu faço não vou conseguir humanizar o que eu faço. Existe muito trabalho mecânico. Eu procuro tratar meu paciente diferente, de uma forma mais humanizada (Técnica de enfermagem 4).

Todos os profissionais relataram já ter ouvido algo sobre a Política de Humanização na Saúde, porém expressaram conteúdos voltados mais à humanização no contexto da UTIN, provavelmente em decorrência dos treinamentos realizados no setor. Entre as menções, encontram-se questões referentes ao acolhimento à família do bebê, medidas para amenizar a dor, medidas para se adequar o ambiente sensorial da unidade neonatal ao bem-estar do RN, além dos laços de solidariedade, como apoio à família e compreensão da condição de hospitalização apresentada pelo paciente.

Outro ponto relacionado à concepção de humanização para os profissionais entrevistados diz respeito aos aspectos da própria assistência, com atenção às especificidades do atendimento em UTIN. Os profissionais ressaltaram os cuidados em relação ao conforto do bebê, seu acolhimento juntamente com a família, além dos cuidados com o contexto da UTIN, entendido como potencializador de sequelas para o RN.

A presença da família foi um aspecto apontado pelos participantes como muito importante para a oferta de assistência integral na unidade neonatal, o que pode ser observado na associação entre as classes Humanização e Participação da Família. O bebê não é visto mais como um ser isolado, mas pertencente à família, a qual deve receber e cuidar de seu novo membro. Dessa forma, a humanização do cuidado ao RN deve priorizar o acolhimento à família e sua participação ativa junto ao bebê.

\section{Participação da família}

Na classe Participação da Família foram expressos os conteúdos referentes à importância do vínculo familiar e às práticas realizadas para incentivar a permanência dos pais na UTIN, a participação destes nos cuidados ao bebê e a presença de outras pessoas do grupo familiar, como irmãos e avós. Destacam-se como palavras mais representativas da classe: mãe, pai, avós, conversa, acompanhar, incentiva, vir, visitas, participação, importância, explicar, família, aleitamento materno, banco de leite, canguru, colo, cuidado, irmão, vínculo, acolhimento, contato e carinho.

Verifica-se por meio dos conteúdos levantados que os profissionais entendem a importância do contato e da participação dos pais junto ao bebê, apontando, para tanto, algumas ações como: os horários de visita, dos quais os avós e irmãos também participam; o incentivo ao aleitamento materno, com o trabalho do Banco de Leite; e o incentivo à posição canguru, ao colo e aos cuidados diretos. Algumas falas representaram essa classe:

Dar orientação, incentivar mãe a estar participando, vindo todo dia, saber o que está acontecendo, amamentando, em contato 
com o neném. Passando informação para os pais. Quando o bebê pode o canguru, a gente incentiva (Médica 1).

Às vezes, eles demoram muito para querer pegar, por medo também. Porque eles ficam doidos para pegar, mas têm medo, aí eu pergunto: você quer pegar? Coloco no colo deles e fico falando: nossa que menino lindo. [...] Eu tento estreitar os laços dos pais com os filhos (Fisioterapeuta 2).

Na categoria Participação da Família as práticas mais relatadas foram conversar com mãe/ pai, incentivar o contato pelo toque o mais precoce possível, permitir a participação dos pais nos cuidados com o bebê e acompanhá-los durante esses cuidados, informar a família sobre as condições do filho, orientar pais e familiares quanto às especificidades da UTIN e do cuidado ao RN. Outras práticas incluíram o incentivo à posição canguru, ao aleitamento materno e maior participação do pai.

\section{Sentimentos em relação ao trabalho}

Nessa classe encontram-se reunidas as falas que expressam os sentimentos dos profissionais em relação ao bebê, à atuação em terapia intensiva neonatal e ao ambiente de trabalho, retratando como os profissionais se sentem quanto ao trabalho e ao cuidado com os neonatos. As palavras plenas mais representativas da classe foram cansada, gosto, penso, casa, sinto, colega, trabalho, cansativo, crescer, desestimulada, dinheiro, doente, adoro, carga horária, chateada, marido, filhos, neonatologia, escolhi, empenho, melhor, prazer e satisfação pessoal.

Sentimentos opostos em relação ao trabalho "se misturam" e se apresentam sobrepostos: por um lado, os profissionais afirmam a escolha profissional pela neonatologia como geradora de satisfação pessoal e prazer e, por outro lado, eles sinalizam as dificuldades de trabalho num serviço de tratamento intensivo e as precárias condições de serviço na área da saúde (trabalho cansativo, desestímulo, carga horária elevada, adoecimento da categoria, dentre outros). Algumas falas são 114 ilustrativas:
Eu adoro trabalhar com neonatologia, para gente é questão de satisfação pessoal estar trabalhando com aquilo que a gente gosta. Então, na questão do atendimento do bebê, para a gente é, principalmente, quando a gente vê que aquele bebê pequenininho cheio de problemas está melhorando, está evoluindo, está crescendo, ganhando peso, ficando bem e indo embora para casa. Então, isso é satisfação pessoal mesmo (Médica 1).

Eu adoro muito o que eu faço. Então eu fico tranquila no meu ambiente de trabalho e as coisas vão acontecendo. Eu estou ali e eu adoro o que eu faço, então é tranquilo (Fonoaudióloga 1).

Aqui é um ambiente um pouco tenso. Tem uma demanda de serviço muito grande, tanto por eu ser responsável por uma equipe e estar orientando, quanto pelas intercorrências que ocorrem normalmente com os bebês, os nascimentos, a manutenção dos equipamentos. Isso tudo influencia muito e causa um estresse (Enfermeira 2).

O trabalho com o RN é apontado como fator positivo, uma vez que os profissionais destacam gostar de trabalhar com bebês/crianças, bem como acompanhar seu desenvolvimento e vê-los sair da UTIN. Por isso, o grupo relatou que se empenha em exercer um atendimento de qualidade.

Há também relatos de sentimentos de impotência em relação ao grave quadro clínico de alguns bebês, comoção pelo seu estado e de sua família, sensibilidade e responsabilidade pela sua melhora e desenvolvimento, bem como angústia devido ao longo tempo de internação dos pacientes, sua separação da família e iminência da morte. Em consonância com a análise do corpus gerada pelo programa Alceste, dentre as principais dificuldades, os profissionais destacaram que seu trabalho é cansativo, angustiante e que possuem uma alta carga horária, além de problemas de hierarquia e falta de materiais.

\section{Estimulação oral}

Na classe Estimulação Oral foram apresentadas as práticas dos profissionais em relação 
ao estímulo oral para o aleitamento materno e também para amenizar a dor do RN. As palavras plenas mais significativas dessa classe foram dedo de luva, sucção, coloco, peito, leite, dieta, estímulo, chupetinha, glicose, chorando, boca, sucção não nutritiva, fonoaudióloga, bico, banho, seio materno, medicação, punção, enrola, aspirar, acalentar, ninho e procedimento doloroso.

O uso da sucção não nutritiva foi a ação mais relatada pelos participantes e cumpre dupla funcionalidade: para o desenvolvimento da sucção (e consequentemente para o aleitamento materno) e para amenizar a dor e o estresse do bebê. As técnicas de sucção não nutritiva, como o dedo de luva e a chupetinha, aparecem como práticas realizadas para ambos os fins. No aleitamento materno, elas foram mencionadas como meio de fazer o bebê desenvolver a sucção, com a estimulação de toda a boca, inicialmente pela dieta por sonda até ser colocado no peito para sugar o leite materno, como destacado a seguir:

No caso dos bebês que não estão sugando, o tal do dedinho não nutritivo, uma gotinha de glicose quando eles não querem pegar. Na hora da dieta colocar o dedinho ou o próprio dedo com luva para estimular a sucção dele (Técnica de enfermagem 2).

A respeito dos procedimentos para amenizar a dor dos bebês, os profissionais relataram a realização da sucção não nutritiva (com utilização do "dedo de luva", glicose ou chupeta) e outras técnicas, como: contenção; ninho; minimização dos estímulos ambientais; enrolamento; cuidado no manuseio; e limite de tentativas nos procedimentos (como na punção venosa). Foi registrada, ainda, a utilização de medicamentos para dor e sedativos de acordo com a prescrição médica.

\section{Cuidados com o ambiente sensorial}

Nessa categoria encontram-se os conteúdos referentes ao manejo do meio ambiente da UTIN e dos procedimentos, com ações visando à adequação da luminosidade, do nível sonoro e da manipulação com o bebê. Destacaram-se como palavras mais representativas da classe: luz, incubadora, barulho, procedimento, ruído, tenta, manuseio, evitar, iluminação, horário, alarme, claridade, portinhola, escuro, dormir, manuseio mínimo, lavar as mãos, higienização, luz apagada e diminuir. Assim, os participantes associaram o cuidado humanizado às intervenções direcionadas ao ambiente sensorial da unidade neonatal, contemplando a adequação da luminosidade, sonoridade e manipulações do RN, como descrito a seguir:

Eu termino o atendimento e apago a luz. Procuro chamar todo mundo, você tem que atender um neném, aí vamos lá. Você tem que fazer o quê? Você tem que aferir sinais, examinar? Aí, o que eu faço, todo mundo faz; eu faço a fisioterapia, vou posicionar, apagar a luz e aí ninguém mais vai mexer nele (Fisioterapeuta 3).

Não bater com a porta na incubadora, evitar bater no berço, tem berço comum lá também, que a gente evita. Ter calma, pegar, ter cuidado de não estar dando pancada na incubadora, batendo a caneta ou prancheta; a gente faz o mínimo possivel, para não ter ruído (Técnica de enfermagem 10).

Várias práticas foram mencionadas para adequar o ambiente sensorial da UTIN à proposta de um ambiente humanizado. Quanto às ações para adequar a iluminação na UTIN, os participantes relataram: apagar as luzes quando os cuidados são finalizados; cobrir a incubadora com paninhos ou lençóis; utilizar toquinhas cobrindo os olhos dos bebês; diminuir a luz; utilizar proteção ocular em bebês quando em fototerapia; realizar agrupamento de cuidados; e intercalar lâmpadas (iluminação individualizada). Outras medidas importantes envolvem cobrir o rosto do bebê e lateralizá-lo para diminuir a intensidade da luz sobre seu rosto.

Quanto às ações para diminuir o nível de ruído na UTIN, os profissionais apontaram os seguintes cuidados: manusear delicadamente a incubadora (não bater, esbarrar ou escrever no equipamento); abrir e fechar as portinholas com cuidado; desligar alarmes prontamente; evitar conversas; falar baixo; promover "horários de silêncio"; e orientar a equipe a deixar o celular no modo silen- 
cioso. Ainda, os profissionais relataram a utilização de protetor auricular no RN em ocasiões de barulho extremo.

Várias ações já assinaladas também foram referidas pelos profissionais como práticas exercidas ao executar procedimentos e manipular os bebês: lavar as mãos e ter higiene; conversar com o bebê; respeitar o estado comportamental do bebê (por exemplo, não manipulá-lo quando está em sono profundo); organizar o bebê no leito; observar os parâmetros clínicos do bebê; separar o material com antecedência; manter a boa postura do bebê; respeitar o mínimo manuseio; e realizar os procedimentos em bloco (agrupar os cuidados). Além dessas práticas, a equipe mencionou o planejamento do procedimento, a delicadeza ao realizar os movimentos, a espera para o bebê se acalmar após a intervenção, e a mudança de decúbito.

\section{Discussão}

No presente estudo, o qual se propôs a investigar as concepções de humanização dos profissionais atuantes em UTIN, verificou-se que os profissionais entrevistados concebem a assistência humanizada como um modo de atenção que se contrapõe ao modelo médico-tecnicista e fundamentado numa perspectiva medicalizante e hospitalocêntrica de saúde (Deslandes, 2006; Martins, 2004). Atualmente, o profissional questiona o processo de despersonalização institucional, que reduz o paciente a sua patologia, bem como sua submissão ao saber médico e a priorização de procedimentos tecnológicos (Silveira, Camargo, \& Crepaldi, 2010; Costa et al., 2009).

$\mathrm{O}$ discurso dos profissionais em relação às concepções e práticas de humanização encontra-se dividido em aspectos relacionais versus aspectos técnicos. Entende-se que essa divisão entre aspectos relacionais e aspectos técnicos decorre da configuração dos processos de atenção à saúde, que se baseia historicamente na valorização dos meios tecnológicos e na execução de tarefas padronizadas e rotinizadas, em detrimento dos aspectos subjetivos 116 do cuidado. O resgate dos fatores relacionais e subjetivos do cuidado à saúde constitui, ainda, um grande desafio para a assistência nessa área, sobretudo nas instituições hospitalares (Ferreira, 2005).

As concepções de humanização dos profissionais de saúde aproximam-se dos princípios norteadores da PNH, fundamentando-se na valorização das relações interpessoais, na consideração do outro como sujeito, nos elementos altruístas do cuidado e na assistência junto às famílias, e entendendo a humanização como elemento oposto ao modelo médico-tecnicista. Nessas concepções, a prevalência dos aspectos relacionais vai ao encontro da proposta da política ministerial que ressalta a mudança no modelo de atendimento em saúde, com o aprimoramento das relações entre profissionais e usuários (Brasil, 2002; 2004).

Os resultados destacados se assemelham aos encontrados por Rolim e Cardoso (2006) e Beck et al. (2007), os quais apontam que a assistência humanizada era percebida por profissionais de saúde a partir do resgate dos aspectos emocionais, do fortalecimento das relações interpessoais e do aprimoramento dos sentimentos internos, caracterizando o cuidado integral. Tais fatores são considerados importantes na produção de mudanças na cultura assistencial, primando-se pela qualidade e integralidade do atendimento ao bebê e sua família.

Os profissionais entendem a humanização a partir de uma reconfiguração da relação paciente-profissional, por meio de uma assistência centrada no respeito ao outro como sujeito, em uma melhor comunicação e orientação do paciente e sua família, e, sobretudo, em seu acolhimento. Esses princípios, pautados nos valores de solidariedade e alteridade, são considerados importantes para a mudança da cultura assistencial (Alves, Deslandes, \& Mitre, 2009; Brasil, 2002; 2005).

Os profissionais destacaram a importância da presença e participação dos pais durante a internação do bebê, estabelecendo uma relação entre atenção humanizada ao RN enfermo e participação da família, resultado também encontrado nos estudos de Henning et al. (2006) e de Rolim e Cardoso (2006). Isso se estabelece por meio de ações de apoio e promoção de condições que facilitem um contato mais próximo com o filho e uma participação mais efetiva dos pais nos cuidados. 
As práticas relatadas pelos profissionais com objetivo de promover a participação da família também foram encontradas nos estudos de Henning et al. (2006), com destaque para o fornecimento de informações claras aos pais e incentivo à sua participação nos cuidados assistenciais. Contudo, as autoras apontam as dificuldades que os profissionais apresentaram, seja para ouvir a demanda da família em relação ao bebê, seja para responder aos questionamentos acerca dos procedimentos de que as mães participavam.

A posição canguru foi destacada pelos profissionais como uma forma de obter maior aproximação entre o bebê e os pais, por meio do contato direto pele a pele, em que não se troca somente calor, mas também carinho e aconchego. Da mesma maneira, o aleitamento materno, além da função primordial de nutrição do RN, indispensável para seu ganho de peso e futura alta, foi referido como uma forma de aproximar mãe e bebê, promovendo a construção de vínculos afetivos entre a díade (Lamy Filho et al., 2008; Venâncio \& Almeida, 2004).

A concepção de humanização dos profissionais esteve também relacionada a seus sentimentos e percepções em relação ao bebê atendido e a seu trabalho em neonatologia. O trabalho em equipe também foi apontado como um aspecto da humanização, na medida em que os profissionais apresentam objetivos comuns e atuam de forma interdisciplinar (Goulart \& Chiari, 2010; Oliveira, Lopes, Vieira, \& Collet, 2006).

Os profissionais ressaltaram que, no cotidiano de trabalho, o desestímulo é grande, devido principalmente à falta de valorização do trabalhador, o que contribui para o processo de adoecimento dos profissionais de saúde (Brasil, 2002; Goulart \& Chiari, 2010; Rolim \& Cardoso, 2006). Nessa direção, Oliveira et al. (2006) apontam que, para o atendimento não se tornar mecanizado e desumano, além dos aspectos relacionados ao bebê e família, é imprescindível considerar que a humanização também inclui as relações profissionais e as condições do ambiente de trabalho.

Os resultados desta pesquisa são semelhantes aos de Beck et al. (2007), os quais indicaram que os profissionais de enfermagem, a despeito do grau de satisfação com o ambiente de trabalho, reclamavam melhores condições para a assistência ao paciente, principalmente no que diz respeito à falta de materiais para a execução do cuidado. A conscientização do profissional sobre sua realidade, com o desenvolvimento de um processo crítico perante sua atuação profissional, é apontada como meio importante para a transformação do cuidado (Goulart \& Chiari, 2010; Oliveira et al., 2006). Assim, esses estudos atestam a premissa de que o profissional é elemento fundamental para a humanização do atendimento, defendendo a realização de investimentos nos serviços de saúde, número suficiente de pessoal, melhor salário e condições adequadas de trabalho.

A realidade expressa no discurso dos participantes aponta a importância da promoção de ações direcionadas ao "cuidado do cuidador", que contemplem a criação de espaços onde eles possam expressar suas vivências das situações cotidianas nas UTIN. Além disso, é importante oferecer treinamento para manejarem situações estressantes, num processo de educação permanente (Beck et al., 2007; Henning et al., 2006; Rolim \& Cardoso, 2006).

Destacando-se o profissional de saúde como elo fundamental no processo de cuidado, após a conclusão da pesquisa, foram realizados encontros com as equipes dos três hospitais para devolutiva dos dados analisados. Além disso, em parceria com outros pesquisadores e profissionais das unidades neonatais, foram ministradas palestras aos profissionais de saúde abordando a temática da humanização e práticas de cuidado em UTIN.

A Unidades de Terapia Intensiva Neonatal é caracterizada como um ambiente de superestimulação para o RN (alto nível de ruído, luminosidade e manipulação), geralmente não contingente às respostas dos bebês e incompatível com sua capacidade de autorregulação. Desse modo, a UTIN constitui fonte de stress e desorganização para o bebê, podendo gerar danos a seu desenvolvimento (Als et al., 2004; Aylward, 2009).

Os cuidados em diminuir a iluminação e o nível de ruído e em manipular corretamente o bebê foram apontados como meio de proporcionar menos stress para ele, além de protegê-lo quanto a 
possíveis sequelas ou problemas em seu desenvolvimento (Brasil, 2002; Hennig et al., 2006). As dificuldades para a execução das práticas de diminuição do nível de ruído e iluminação na UTIN e a consequente resistência em realizá-las plenamente, foram justificadas pela necessidade de monitoramento constante dos parâmetros dos bebês, pela grande quantidade de pessoas circulando na UTIN, e pela falta de bom senso de alguns profissionais.

Quando se pensa na qualidade de vida dos RN internados em UTIN, percebe-se a necessidade de intervenções no ambiente sensorial da unidade neonatal, com vistas a diminuir o nível de estimulação, garantindo-lhes uma melhor maturação física e neurológica (Als et al., 2004; Aylward, 2009). A estimulação, quando adequada, proporciona benefícios para o bebê, tornando-se assim de extrema relevância a adequação do nível dos estímulos à condição evolutiva do RN e às suas necessidades individuais (Brasil, 2002; Lamy, Gomes, Gianini, \& Henning, 2005).

A assistência humanizada supõe uma reestruturação do serviço de saúde, conjugando "tecnologia" e "fator humano e de relacionamento", configurando duas formas de cuidar que se inter-relacionam na prestação do atendimento ao paciente (Deslandes, 2004). A AHRNBP-MC pode ser caracterizada pela qualificação do cuidado baseada na postura da equipe de saúde diante do bebê e sua família, não limitando a assistência aos conhecimentos técnico-científicos. Desse modo, o profissional será capaz de contribuir de forma integrada, tanto para a diminuição dos efeitos deletérios da internação sobre o desenvolvimento da criança, quanto para a constituição de uma significativa rede de apoio à família, auxiliando no enfrentamento dos recorrentes estressores presentes na UTIN.

\section{Referências}

Als, H., Duffy, F. H., McAnulty, G. B., Rivkin, M., Vajapeyam, S., Mulkern, R. V., ..., Eichenwald, E.C. (2004). Early experience alters brain function and structure. Pediatrics, 113(4), 846-857.

Alves, C. A., Deslandes, S. F., \& Mitre, R. M. A. (2009). Desafios da humanização no contexto do cuidado da enfermagem pediátrica de média e alta complexidade. 118
Aylward, G. P. (2009). Neonatology, prematurity and developmental issues. In M. C. Roberts, \& R. G. Steele, (Eds.), Handbook of pediatric psychology ( $4^{\text {th }}$ ed., pp.241-253). New York: The Guilford Press.

Bardin, L. (2004). Análise de conteúdo (3a ed.). Lisboa: Editora 70.

Beck, C. L. C., Gonzales, R. M. B, Denardin, J. M., Trindade, L. de L., \& Lautert, L. (2007). A humanização na perspectiva dos trabalhadores de enfermagem. Texto e Contexto Enfermagem, 16(3), 503-510.

Brasil. Ministério da Saúde (2002). Secretaria de Políticas de Saúde. Atenção humanizada ao recém-nascido de baixo peso: método Canguru: manual do curso. Brasília: Ministério da Saúde. Série A. Normas e Manuais Técnicos.

Brasil. Ministério da Saúde. (2004). Núcleo Técnico da Política Nacional de Humanização. Política nacional de humanização: a humanização como eixo norteador das práticas de atenção e gestão em todas as instâncias do SUS. Brasília: Ministério da Saúde. Série B. Textos Básicos de Saúde. Recuperado janeiro 20, 2008, de http://bvsms.saude.gov.br/bvs/humanizaçao/pub_ destaques.php

Brasil. Ministério da Saúde. (2005). Núcleo Técnico da Política Nacional de Humanização. Humaniza SUS e as redes sociais. Brasília: Ministério da Saúde. Série B. Textos Básicos de Saúde. Recuperado janeiro, 20, 2008, de http://bvsms.saude.gov.br/bvs/humanizaçao/ pub_destaques.php

Camargo, B. V. (2005). Alceste: um programa informático de análise quantitativa de dados textuais. In A.S.P Moreira, J.C Jesuino, \& B.V. Camargo (Orgs.), Perspectivas teórico-metodológicas em representações sociais (pp.511-539). João Pessoa: Editora Universitária da UFPB.

Cortez, M. B. (2006). Maridos dominadores, esposas (in)subordinadas: as implicações do empoderamento feminino e da masculinidade hegemônica na violência conjugal (Dissertação de mestrado não-publicada). Universidade Federal do Espírito Santo.

Costa, S. C., Figueiredo, M. R. B., \& Shawrich, D. (2009). A humanização em Unidade de Terapia Intensiva adulto (UTI): compreensões da equipe de enfermagem. Interface: Comunicação, Saúde, Educação, 13(Supl.1), 571-580.

Cunha, A. C. B., \& Benevides, J. (2012). Prática do psicólogo em intervenção precoce na saúde maternoinfantil. Psicologia em Estudo, 17(1), 111-119.

Deslandes, S. F. (2004). Análise do discurso oficial sobre a humanização da assistência hospitalar. Ciência e Saúde Coletiva, 9(1), 7-14.

Deslandes, S. F. (2006). Humanização: revisitando o conceito a partir das contribuições da sociologia médica. In S. F., Deslandes (Org.), Humanização dos cuidados em saúde: conceitos, dilemas e práticas (pp.33-48). Rio de Janeiro: Fiocruz. 
Ferreira, J. (2005). O programa de Humanização da saúde: dilemas entre o relacional e o técnico. Saúde e sociedade, 14(3), 111-118.

Goulart, B. N. G., \& Chiari, B. M. (2010). Humanização das práticas do profissional de saúde: contribuições para reflexão. Ciência \& Saúde Coletiva, 15(1), 255-268.

Hennig, M. A. S., Gomes, M. A. S. M., \& Gianini, N.O.M. (2006). Conhecimentos e práticas dos profissionais de saúde sobre a "atenção humanizada ao recém-nascido de baixo peso: método canguru". Revista Brasileira de Saúde Materno Infantil, 6(4), 427-436.

Kernkraut, A. M., \& Andreoli, P. B. A. (2008). Humanização em UTI Neonatal. In E. Knobel, P. B. A. Andreoli, \& M. R. Erlichman (Orgs.), Psicologia e humanização: assistência aos pacientes graves (pp.271-280). São Paulo: Atheneu.

Lamy, Z. C. (2006). Metodologia Canguru: facilitando o encontro entre o bebê e sua família na UTI Neonatal. In M.E.L. Moreira, N. A. Braga, \& D.S. Morsch (Orgs.), Quando a vida começa diferente: o bebê e sua família na UTI Neonatal (pp.141-156). Rio de Janeiro: Editora Fiocruz.

Lamy, Z. C., Gomes, M. A. S. M., Gianini, N. O. M., \& Hennig, M. A. S. (2005). Atenção humanizada ao recém-nascido de baixo peso: método canguru: a proposta brasileira. Ciência e Saúde Coletiva, 10(3), 659-668.

Lamy Filho, F, Silva, A. A., Lamy, Z. C., Gomes, M. A., Moreira, M. E., Grupo de Avaliação do Método Canguru, \& Rede Brasileira de Pesquisas Neonatais. (2008). Evaluation of the neonatal outcomes of the kangaroo mother method in Brazil. Jornal de Pediatria, 84(5), 428-435.
Martins, A. (2004). Biopolítica: o poder médico e a autonomia do paciente em uma nova concepção de saúde. Interface: Comunicação, Saúde, Educação, 8(14), 21-32.

Nascimento, A. R. A., \& Menandro, P. R. M. (2006). Análise lexical e análise de conteúdo: uma proposta de utilização conjugada. Estudos e Pesquisas em Psicologia, 6(2), 72-88.

Oliveira, B. R. G., Lopes, T. A., Viera, C. S., \& Collet, N. (2006). O processo de trabalho da equipe de enfermagem na UTI Neonatal e o cuidar humanizado. Texto \& Contexto - Enfermagem, 15, 105-113.

Rolim, K. M. C., \& Cardoso, M. V. L. M. L. (2006). O discurso e a prática do cuidado ao recém-nascido: refletindo sobre a atenção humanizada. Revista Latino-Americana de Enfermagem, 14(1), 85-92.

Silveira, S. C., Camargo, B. V., \& Crepaldi, M. A. (2010). Assistência ao parto na maternidade: representações sociais de mulheres assistidas e profissionais de saúde. Psicologia: Reflexão e Crítica, 23(1), 1-10.

Venancio, S. I., \& Almeida, H. (2004). Método Mãe Canguru: aplicação no Brasil, evidências científicas e impacto sobre o aleitamento materno. Jornal de Pediatria, 80(5), 173-180.

Verás, R. M., Vieira, J. M. F., \& Morais, F. R. R. (2010). A Maternidade prematura: o suporte emocional através da fé e religiosidade. Psicologia em Estudo, 15(2), 325-332.

Recebido: dezembro 10, 2012

Versão final: maio 24, 2013

Aprovado: setembro 23, 2013 
